\title{
EFSUMB Statement on Medical Student Education in Ultrasound [long version]
}

Authors

Affiliations
V. Cantisani ${ }^{1}$, C. F. Dietrich ${ }^{2}$, R. Badea ${ }^{3}$, S. Dudea ${ }^{4}$, H. Prosch ${ }^{5}$, E. Cerezo ${ }^{6}$, D. Nuernberg 7 , A. L. Serra ${ }^{8}$ P. S. Sidhu ${ }^{9}$, M. Radzina ${ }^{10}$, F. Piscaglia ${ }^{11}$, M. Bachmann Nielsen ${ }^{12}$, C. Ewertsen ${ }^{13}$, A. Săftoiu ${ }^{14}$, F. Calliada ${ }^{15}$, O. H. Gilja

Affiliation addresses are listed at the end of the article
Key words

- education

- ultrasound

medical

\section{Abstract \\ $\nabla$}

The European Federation of Societies for Ultrasound in Medicine and Biology (EFSUMB) recommends that ultrasound should be used systematically as an easy accessible and instructive educational tool in the curriculum of modern medical schools. Medical students should acquire theoretical knowledge of the modality and hands-on training should be implemented and adhere to evidence-based principles. In this paper we report EFSUMB policy statements on medical student education in ultrasound that in a short version is already published in Ultraschall in der Medizin [1].

\section{Kurzfasung}

$\nabla$

Die Europäische Ultraschallgesellschaft EFSUMB (European Federation of Societies for Ultrasound in Medicine and Biology) empfiehlt die systematische Lehre von Ultraschall als Teil des modernen universitären (studentischen) Curriculums. Medizinstudenten sollten im Rahmen Evidenzbasierter Lehrkonzepte theoretisches Wissen erwerben und praktische Übungen durchführen. In dem hier vorgestellten EFSUMB Positionspapier werden Kernaussagen der sonographischen Studentenausbildung zusammengefasst. received $\quad$ 14.01.2016

accepted 15.01.2016

Bibliography

DOI http://dx.doi.org/

10.1055/s-0035-1569413

Ultrasound International Open

2016; 2: E2-E7

(c) Georg Thieme Verlag KG

Stuttgart · New York

ISSN 2199-7152

Correspondence

Prof. Dr. med. Christoph F.

Dietrich

Med Klinik 2

Caritas Krankenhaus

Uhlandstr. 7

D-97980 Bad Mergentheim

Germany

Tel.: + 49/7931/58 2201

Fax: $+49 / 7931 / 582290$

christoph.dietrich@ckbm.de

\section{License terms}

\section{Introduction}

\section{$\nabla$}

"Education is the most powerful weapon which you can use to change the world"

(Nelson Mandela)

Ultrasound is an effective method used throughout the world for clinical work-up of patients with a wide range of diseases, particularly as first line imaging modality. Technological advancements have made the equipment accessible and affordable up to hand-held ultrasound devices that are now about the size of a smart phone [2-4]. Moreover, hand-held ultrasound has the potential to extend the physical examination validating the doctor's clinical findings. Technological progress has opened new perspectives to ultrasound (US) clinical applications. Accordingly, education and subsequently preparation and updating of US knowledge become crucial [5]. EFSUMB (European Federation of Societies for Ultrasound in Medicine and Biology) [6] and others [7] have published atlas on anatomy and examination technique of handheld devices.
Certified radiologists must master this imaging modality while most of other medical specialists also perform ultrasound in their daily practice. The easy accessibility and increased utility indicate that all future physicians should have knowledge of ultrasound. However, its place in the curriculum of medical schools is currently very variable and has not been defined yet [8]. Medical student education is traditionally based on "classical" training methods such as presentations, courses and workshops. However, new technologies and web-based sources of information have opened novel educational applications in medical practice [8]. Various methods that are used in medical practice, especially imaging and surgical techniques, but also clinical and observational methods, may have educational value and are useful in student's education.

Ultrasound scanning by students is among the most recently introduced subjects in the medical curriculum [9]. Some universities and authors have advocated that US can be effectively used to teach medical anatomy and physiology, not only for diagnostic imaging [10-13]. The ultrasound equipment may be used in order to generate 
educational content for medical students and residents. Some authors have referred to it as the "sonoscope" or "echoscope" highlighting the use of US as a tool even more important than the stethoscope $[4,14,15]$. The use of US beyond departments of radiology has often been termed "point of care" US. Furthermore, some medical schools, taking advantage of recent technical advances in portable US technology, have started to incorporate education in US within the medical school curriculum $[10-12,16,17]$. Both the Society of Radiologists in Ultrasound and the Alliance of Medical School Educators in Radiology (AMSER) state that radiologists should play an important role in the formation of an US curriculum.

In 2011, Hoppmann reported their first 4 years of experience at the University of South Carolina of Medicine where was introduced an integrated ultrasound curriculum across the 4 years of School of Medicine was introduced for all the students [10]. More recently, Baltarowich et al. [18], proposed a two-folded curriculum organized as follows:

- Pre-clinical: Utilization of US to enhance student understanding of anatomy, physiology and pathology.

- Clinical: Teach students how to use US effectively as a problem-solving tool in the diagnosis of disease.

\section{Preclinical Curriculum}

\section{$\nabla$}

If an ultrasound curriculum is integrated into the overall curriculum, it has the potential to supplement the general understanding of anatomy, physiology and pathology [19]. This horizontal incorporation of an US curriculum is probably best organized and implemented by a multidisciplinary group including internal medicine, radiology, and experienced US specialists with the course directors of the anatomy, physiology, and pathophysiology preclinical courses. Hands-on sessions can also be incorporated into a physical diagnosis course. Ideally, the curricular content would be taught in didactic lectures and smallgroup sessions, enriched by the experience and contribution of US imaging experts. This would include 1 or 2 introductory lectures in US physics, image acquisition, indications, and limitations. Alternatively, some medical schools may choose a more vertical approach, assigning specific hours to ultrasound imaging for didactics and workshops to cover the complete preclinical curriculum.

By applying the constructivist theory of learning the content can be separated into several sessions over the 2 preclinical years to allow building on prior content to improve understanding and retention [20].

In the horizontal and vertical integrated form of curriculum the clinical ratio increases to the end of study. US curriculum has to follow an organ and topic based module system (movement, circulation, respiration, digestion, inflammation, coordination, etc.) and has to involve clinical parts from the beginning to the end [21-24].

\section{Clinical Curriculum}

$\nabla$

Some models of US education were developed. One offers graduated levels of exposure and imaging experience for medical students during third-year clerkships (Harvard Medical School, Boston, USA) [25]. The second model is more compact, organized as a dedicated 3-day program (Thomas Jefferson University
Hospital, Philadelphia, USA) [18]. With the current wide variability in clinical clerkship requirements, it is conceivable that a student could complete a medical school curriculum without ever directly scanning a patient with US. Although not optimal, the authors recognize that US imaging is largely skill based and requires hands-on training to achieve competency. To achieve this goal in a busy clinical setting, the "teach-the-teacher" concept can be applied to recruit experienced students for US teaching. Furthermore, these concepts can be extended by blended learning methods, which have a positive and supporting effect on US education [26]. It could be shown that undergraduate ultrasound tuition is an achievable educational goal which is well received by medical students [27].

Students also need to learn the limitations of US and recognize situations when other imaging modalities may be more appropriate. The authors stated that the proposed curriculum is comprehensive and teaching all elements may not be feasible at any given institution. In particular, the inclusion of the "hands-on" portion is labor intensive. Introducing this curriculum into preexisting courses may increase the likelihood of successful implementation.

Although current medical school curricula have little room for additional content, didactics and teaching, we believe that it is essential to include the basics of US in the greater framework of general medical education [28-30].

One of the first descriptions originates from the Hannover Medical School where they combined anatomy course with hands-on ultrasound workshops performed by medical students on other students [31]. As previously shown, students were satisfied learning anatomy by using ultrasound which at the same time proved to be a highly effective method for facilitating learning and significantly enhancing knowledge of live anatomy [32,33]. After theoretical lectures on "Anatomy", they have one lecture in "Hands-on Ultrasound". First trained on general US and practical management of the US scanner, after which they are trained in sonoanatomy, but always under supervision. Each student is trained $10-12 \mathrm{~h}$ using US during the course. The US equipment is always at the practice hall, with a bed, clean paper and gel. In addition, there are general sessions on US and throughout multimedia resources are available with the US scanner connected to them. On each practice table there is an external monitor. Small number groups of students rotate on the multimedia practices. In addition, the students are provided with anatomy atlases corresponding to dissection levels. Theoretical knowledge ("knows" and "knows how") is the necessary foundation and based upon focused clinical competence that must be built. This can be acquired through books on ultrasound or be taught in traditional classes or at lectures.

Another possibility is to do the performance in a simulated environment, e.g., scanning of fellow students or using simulators. This hands-on training is necessary before reaching the top level of competence ("does") with actual performance on patients. Heinzow et al. [11] published the results of a pilot study in which 240 medical students of the University of Munster during 2010 and 2011 in their $4^{\text {th }}$ year of undergraduate medical education participated in the training and completed a pre- and post-questionnaire for self-assessment of technical knowledge, self-assurance of the procedure, and motivation in performing ultrasound applying the DEGUM sonographic guidelines for undergraduate medical students [34]. The complete curriculum consisted of $28 \mathrm{~h}$ over 9 weeks. The practical training encompassed $20 \mathrm{~h}$, consisting of 10 sessions each lasting $2 \mathrm{~h}$. The sessions were 
accompanied by weekly lectures focusing on 9 different session themes addressing the basics of ultrasound techniques, physics and tools, abdominal and pelvic anatomy, thyroid gland, Focused Assessment with Ultrasound for Trauma (FAST) and general pathologies. There was a significant increase in technical knowledge and self-assurance $(\mathrm{p}<0.001)$ of the student self-assessment. The clinical relevance and self-motivation of the teaching were evaluated positively. Therefore, the authors concluded that simulated training in a highly professional undergraduate setting is possible and can be integrated in a curricular theme in medical school education, and further has a positive impact on increased physician expertise with diagnostic imaging technology and may improve the quality of patient care. The application of the educational method of simulation to ultrasound has made this one of the top ranking courses within the educational activities. Unfortunately, we have to take in consideration that this system may require a lot more resources than traditional lectures and self-study. Expensive ultrasound training should be established according to best available evidence in order to ensure optimal learning output. An ultrasound scanner or simulator per student provides maximum hands-on time but a recent study on the effects of simulator-based ultrasound training found that training in pairs ("dyad practice") actually improved the efficacy of training and was not inferior to individual practice in terms of skills transfer [35]. Virtual-reality simulators deliver a multitude of different "standardized patients" that can be used for teaching pathology and traumatology although the simulators are costly and their fidelity is still not optimal [36]. Performing ultrasound assessment with established pass/fail standards at the end of ultrasound courses can also increase motivation and the retention of skills $[37,38]$.

National responses to surveys reported on the actual status of student education in ultrasound and showed non-uniform and adequate inclusion of US in the core curriculum of student medical education with some exceptions [39].

In conclusion we refer to the words from Solomon et Saldana: "A generation of physicians will need to be trained to view this technology as an extension of their senses. That development will require the medical education community to embrace and incorporate the technology throughout the curriculum" [40].

\section{EFSUMB Strategy \\ $\nabla$}

EFSUMB has prepared an EFSUMB Course Book (ECB) [41], EFSUMB Course Book Student Edition (ECBSE) [42], Atlas on echoscopy [6] and teaching videos (anatomy, examination technique) [43] which are free to download from the EFSUMB website (www.efsumb.org) [44].

EFSUMB has decided to establish a separate Student Committee in the federation that will promote student education and relevant activities in Europe. EFSUMB is now undertaking work to make new bylaws and recruit students from different European countries in an interim board. Furthermore, EFSUMB will launch a new Student Congress that will be integrated with future Euroson congresses.

The Educational and Professional Standard Committee (EPSC) of EFSUMB aim to initiate and monitor international co-operative studies on student training in medical ultrasound. The steps proposed are:

- To review the present knowledge on student education and the previous reported experiences.
- To forward an official letter as a consequence of the above mentioned survey informing the different universities who answered, and to all the national universities including the student representative organizations about the proposal of EFSUMB for the inclusion of US in the medical education core curriculum.

- To provide e-learning resources that can be used for US student education, e.g., EFSUMB educational portal.

- To inform relevant medical schools throughout Europe about the recommended curriculum and the available resources in EFSUMB, and to promote the implementation of US education.

- To launch a one-year prospective integration of anatomy and physiology teaching by means of US in 4-6 selected universities and providing specific appendix of core curriculum.

EFSUMB recommends that ultrasound should be used systematically as an easy accessible and instructive educational tool in the curriculum of modern medical schools. Medical students should acquire theoretical knowledge of the modality and hands-on training should be implemented and adhere to evidence-based principles. In our opinion, it is due time to introduce US education programs at european universities to provide our students knowledge and skills to be able to take care of patients' diagnosis and therapy in the best possible way.

The pilot project aims to improve the quality of training received by the medical students enrolled in medical universities, by elaborating and implementing a system which proposes an upgrading of the methods of teaching and learning ultrasound using ultrasound images as key tools: "anatomy and physiology training of students using ultrasound". This project may represent a part of a larger process of curricula modernization as well as reformation of methods used in present medical training. The first activity was an EFSUMB survey on US student education status in Europe.

\section{Target groups}

- Main Group: medical specialty students (anatomy and physiology courses).

- Secondary Group: members of the teaching staff involved in the project.

\section{Objectives (Appendix 1)}

2 categories of objectives have been defined:

- General objectives - upgrading of the quality of anatomy knowledge and training received by Medical School students;

- Specific objectives - which are to be reached at the end of each year (cycle) of study, in relationship with each medical discipline that benefits from the support of ultrasound

\section{Material and Methods \\ $\nabla$}

EFSUMB recently published a student edition of the course book for free download at http://www.efsumb.org. This textbook will be updated and will be available for use by students during training together with all the material derived from websites and journals. All the videos and material content present in the Verified Learning site and in the educational Portal will be adequately revised and adapted to the target group (students). Specific lessons on US anatomy of superficial, abdominal organs, vessels, heart and muscles will be prepared and followed by 
hands-on live presentation and tutorial courses offering selfassessment by the participants.

Modalities to accomplish the educational objectives

- The activities developed during the preclinical cycle of education (years I-II) with US assistance will aim to facilitate the understanding and integration of the main aspects of anatomy, physiology, morphopathology and physiopathology (pathology) by the students.

- Educational activities assisted by US will be as direct as possible and linked to the basic educational activities, avoiding overloading the student with excessive additional information. Simple medical scenarios where US will be used for all clinical activities.

- Talented medical students themselves will participate as subjects and eventually active teachers (after a course) in order to demonstrate the normal basic US aspects.

- An internet (web) based communication between the teaching staff and the students, will be initiated and developed. The creation of a project-related "forum" for the students is a recommended communication platform.

The curriculum of the themes covered and developed in the project (Appendix 2 will contain aspects specific to each of the partner disciplines.

\section{Strategy (Appendix 3)}

Identification of the disciplines which are part of the university curriculum and which may benefit from the support of US for the specific training for the students.

1. Establishing subjects of the identified disciplines where US assisted training activities will be introduced.

2. The development of a partnership system among the departments involved in the project: anatomy, physiology departments as well as all clinical departments that employ ultrasound in daily practice should all be involved.

3. Realizing a minimal specific curriculum with a definition of the areas where ultrasound will be introduced. This curriculum must contain the necessary information for each year of study and must be in relationship with the partner disciplines in order to be introduced in the training schedule, without altering the structure of the present curriculum as a whole. (This should not involve changes in the hourly volume or the amount of requirements from students!).

4. Identification, formation and establishment of the human resources (training staff, tutors). The teaching staff must have robust ultrasound knowledge and preferably be practicing clinicians. Formation of teaching instruments as support for courses (ultrasound manuals, courses, workbooks for each year of study, images database).

5. Implementation of the project beginning with the first year and respectively within the third year of study. At the end of 3 years cycle an overall evaluation should be performed.

6 . All the decisions regarding the content and structure of the educational activities that benefit from the assistance of ultrasound, will be taken only after an analysis is performed in cooperation with the curricula development office and after the approval of the leadership of the university/medical schools.

\section{Human resources}

The tutors (trainers, educators) will be organized as follows:

- Permanent. The members of the teaching team that practice ultrasound at a high level of competence (trainer, expert) will be identified in each of the partner disciplines.

- Temporary - complementary. Volunteer trainers, residents, $\mathrm{PhD}$ students, final year students, imaging and sonographers according to local national organizations.

\section{Observations}

- There will be a coordinator inside each of the partner disciplines.

- The trainers will be invited and instructed to realize teaching aids using interactive software centered on graphic tablets, with the purpose to increase adherence and accessibility.

- The development of teaching aids must be regarded as a continuous process, developed and improved as experience is achieved and in relationship with the technical progress.

\section{Material and Logistic Resources}

\section{$\nabla$}

Ultrasound manuals (EFSUMB Student Edition - ECBSE)| course notes

- It will consist of a short material containing serial US information according to the curriculum

- It will contain the essentials about the US image, comparative anatomical sections, basic images which must be known, simple clinical scenarios

- The focus will be on dynamic images and will be realized in a digital format in order to have an interactive character (text, image, voice).

- The manual will be available for access through the Cloud or on the server of the medical school

- It will be associated with a portal which will ensure the interactivity between the trainer and the student, with the purpose to allow communication, evaluation of knowledge and evaluation of the education through the student.

- EFSUMB ECBSE and other specific books, articles and material.

- Webinar material, website material from EFSUMB, AIUM etc.

\section{US Skills Lab: The Centre for Medical Skills and} Simulation should incorporate an Ultrasound Skills Lab (USSL)

- US equipment - will be used by the students under surveillance. The lab should be provided with 3-4 ultrasound machines for every 100 students (or 1 machine for $4-5$ students at the same time).

- The availability of small, portable machines for performing point of care ultrasound during the clinical clerkships is advised.

- US models (simulating patients) and sonographic simulators have to be available

- Educational software - specific for each year and topic or module of study in order to complete the theoretical teaching

- US manuals in hand library

- US video and image library

- Apple, Windows, Linux software computers

- Apple and Android graphic tablets 


\section{Evaluation of the acquired information}

This will be realized in an integrated manner, as part of the final evaluation (exam) of each of the disciplines involved in the project, by introducing US questions in relationship with the presented subjects.

\section{Project evaluation}

The project must undergo repeated evaluations in order to immediately implement any possible corrections as the project develops:

- At the end of each semester (after each exam session or at the end of a large clinical module).

- At the end of each year of study.

- At the end of the preclinical/clinical cycle.

The evaluation process of medical education using ultrasound as a support tool requires the participation of various distinct factors:

- The school of medicine, dedicated curricular committees.

- The training staff involved in the project.

- Students of the school of medicine.

Other possible evaluation may be held comparing results with the previous year in which no US was used.

\section{Strategy}

Schedule of the project implementation activities

1. Presentation of the final form of the project and achievement of the final agreement from the school of medicine

- Presentation of the project in front of the leadership of the university and the curricula development office

- Definition of the years of study at which the project starts (in relationship with the present curriculum)

- Nominations of the participating disciplines and the sequence of their involvement

- Approval for curricula changes in the university council

\section{Involvement of the participating departments}

- Staff meetings of the involved departments where the curricula are discussed and agreed upon

- Modeling and remodeling of the curriculum - with preservation of the hourly volume (insertion, modalities, place of development, activities)

- An accurate definition of responsibilities (leading and coaching)

- Stage evaluation (data, procedure)

\section{Project development}

- Evaluation after each module of anatomy/year of study/cycle of study

- A synthesis of the evaluations with recommendations/ solutions for improvement

- Continuous improvement of the activities, in relationship with the stage evaluations

- Creating, as the project develops, the necessary educational support

- Objectives, dates and regularity of the meetings of the work group - the group which works directly with the students and the one that coordinates the project
- Re-orientation/supplementation with specific and secondary objectives, in relationship with the results of the evaluations

- Increase of the number and quality of the human resources, in relationship with the progressive increase of the teaching requirements

- Qualitative growth of the infrastructure - sonographic equipment, dedicated website, US images database, various educational supports (hardcopy, but especially digital data, compatible for tablets/smartphones use; forums)

- The activities developed during clinical training will focus on using ultrasound as a complementary method in understanding the signs, symptoms, the syndrome and the disease. An important achievement will be the concept "use ultrasound guidance in invasive procedures whenever appropriate"

\section{- Conclusion}

In the present paper EFSUMB Task Force on US student education reviewed the present knowledge and experiences on US student education highlighting the possibility to integrate US in the student medical education that was already reported in a short version in Ultraschall in der Medizin [1]. A proposal for this purpose will be sent to all the universities and the industries and the student representation society in order to evaluate how to implement US in student medical education. One year of anatomy and physiology teaching by using US will be promoted in 5-6 universities. At the end of this phase a consensus conference promoted by EFSUMB task force, the student European organizations, with worldwide experts and the representative deans of universities will be held to discuss and prepare the future steps.

\section{Affiliations}

Department of Radiological Sciences, Oncology and Pathology, Policlinico Umberto I, University Sapienza, Rome, Italy

${ }^{2}$ Medizinische Klinik 2, Caritas Krankenhaus Bad Mergentheim,

Bad Mergentheim

${ }^{3}$ Department of Ultrasonography, 3rd Medical Clinic, Institute of Gastroenterology and Hepatology Octavian Fodor; Imaging Department, University of Medicine and Pharmacy luliu Hatieganu, Cluj Napoca, Romania

${ }^{4}$ Radiology Department "Iuliu Hatieganu" Univ. Med. Pharm. Cluj-Napoca,

Romania

Department of Biomedical Imaging and Image-Guided Therapy, Medical University of Vienna, Vienna General Hospital, Austria

${ }^{6}$ Calle Francisco Silvela \#124, lo 3 Madrid, Spain

Department of Gastroenterology, Brandenburg University of Medicine Theodor Fontane, Neuruppin

${ }^{8}$ Department of Internal Medicine and Nephrology, Ultrasound Learning Center, Hirslanden Clinic, Zürich, Switzerland

${ }^{9}$ Department of Radiology, King's College Hospital, London, UK

${ }^{10}$ Diagnostic Radiology Institute, Paula Stradins Clinical University Hospital, Riga, Latvia

${ }^{11}$ Unit of Internal Medicine, Department of Medical and Surgical Sciences, University of Bologna, Italy

${ }^{12}$ Department of Radiology, Rigshospitalet, Copenhagen University Hospital, Copenhagen, Denmark

${ }^{13}$ Department of Radiology, Rigshospitalet, Copenhagen University Hospital, Copenhagen, Denmark

${ }^{14}$ Gastroenterology Department, Research Center of Gastroenterology and Hepatology, University of Medicine and Pharmacy Craiova, Romania

${ }^{15}$ Policlinico San Matteo Pavia, Italy

${ }^{16}$ National Centre for Ultrasound in Gastroenterology, Haukeland University Hospital, Bergen and Department of Clinical Medicine, University of Bergen, Norway 


\section{References}

1 Cantisani V, Dietrich CF, Badea $R$ et al. EFSUMB statement on medical student education in ultrasound (short version). Ultraschall in Med 2016; 37: 100-102

2 Mirabel M, Celermajer D, Beraud AS et al. Pocket-sized focused cardiac ultrasound: strengths and limitations. Arch Cardiovasc Dis 2015; 108: 197-205

3 Barreiros AP, Cui XW, Ignee A et al. EchoScopy in scanning abdominal diseases: initial clinical experience. $Z$ Gastroenterol 2014; 52: 269-275

4 Gilja $\mathrm{OH}$, Piscaglia F, Dietrich C. EFSUMB - European Course Book. Echoscopy - A new concept in mobile ultrasound 2014; 1-21

5 Mircea PA, Badea R, Fodor D et al. Using ultrasonography as a teaching support tool in undergraduate medical education - time to reach a decision. Med Ultrason 2012; 14: 211-216

6 Dietrich $C F$. An atlas of echoscopy using a handheld device. www. efsumb.org 2015;

7 Dietrich CF. Ultraschall in der Lehre, ein kleiner Atlas der Echoskopie. Gastroenterologie Up2date 2014; 10

8 Konge L, Albrecht-Beste E, Bachmann Nielsen M. Ultrasound in PreGraduate Medical Education. Ultraschall Med 2015; 36: 213-215

9 Fodor D, Badea R, Poanta L et al. The use of ultrasonography in learning clinical examination - a pilot study involving third year medical students. Med Ultrason 2012; 14: 177-181

10 Hoppmann RA, Rao VV, Poston MB et al. An integrated ultrasound curriculum (iUSC) for medical students: 4-year experience. Crit Ultrasound J 2011; 3: 1-12

11 Heinzow HS, Friederichs $H$, Lenz $P$ et al. Teaching ultrasound in a curricular course according to certified EFSUMB standards during undergraduate medical education: a prospective study. BMC Med Educ 2013; 13: 84

12 Bahner DP, Adkins EJ, Hughes D et al. Integrated medical school ultrasound: development of an ultrasound vertical curriculum. Crit Ultrasound J 2013; 5: 6

13 Bahner DP, Royall NA. Advanced ultrasound training for fourth-year medical students: a novel training program at The Ohio State University College of Medicine. Acad Med 2013; 88: 206-213

14 Greenbaum $L D$. It is time for the sonoscope. J Ultrasound Med 2003; 22: 321-322

15 Gillman LM, Kirkpatrick AW. Portable bedside ultrasound: the visual stethoscope of the 21st century. Scand J Trauma Resusc Emerg Med 2012; 20: 18

16 Arger PH, Schultz SM, Sehgal CM et al. Teaching medical students diagnostic sonography. J Ultrasound Med 2005; 24: 1365-1369

17 Griksaitis MJ, Scott MP, Finn GM. Twelve tips for teaching with ultrasound in the undergraduate curriculum. Med Teach 2014; 36: 19-24

18 Baltarowich OH, Di Salvo DN, Scoutt LM et al. National ultrasound curriculum for medical students. Ultrasound Q 2014; 30: 13-19

19 Swamy M, Searle RF. Anatomy teaching with portable ultrasound to medical students. BMC Med Educ 2012; 12: 99

20 Brunner J. Toward a Theory of Instruction. MA: Harvard University; 1966

21 FrankJR, Snell LS, Cate OT et al. Competency-based medical education: theory to practice. Med Teach 2010; 32: 638-645

22 Schmidt HG, Machiels-Bongaerts $M$, Hermans $H$ et al. The development of diagnostic competence: comparison of a problem-based, an integrated, and a conventional medical curriculum. Acad Med 1996; 71: 658-664

23 Dahle LO, Brynhildsen J, Behrbohm Fallsberg $M$ et al. Pros and cons of vertical integration between clinical medicine and basic science within a problem-based undergraduate medical curriculum: examples and experiences from Linkoping, Sweden. Med Teach 2002; 24: 280-285
24 Dochy $f$, Segers $M$, Van den Bossche P. Effects of problem-based learning: A meta-analysis. Learning and Instruction 2003; 13: 533-568

25 Di Salvo DN, Clarke PD, Cho CH et al. Redesign and implementation of the radiology clerkship: from traditional to longitudinal and integrative. J Am Coll Radiol 2014; 11: 413-420

26 Hempel D, Sinnathurai S, Haunhorst S et al. Influence of case-based e-learning on students' performance in point-of-care ultrasound courses: a randomized trial. Eur J Emerg Med 2015;

27 Gogalniceanu P, Sheena Y, Kashef E et al. Is basic emergency ultrasound training feasible as part of standard undergraduate medical education? J Surg Educ 2010; 67: 152-156

28 Garcia de Casasola Sanchez G, Gonzalez Peinado D, Sanchez Gollarte A et al. Teaching of clinical ultrasonography to undergraduates: students as mentors. Revista clinica epanola 2015; 215: 211-216

29 Kondrashov P, Johnson JC, Boehm K et al. Impact of the clinical ultrasound elective course on retention of anatomical knowledge by second-year medical students in preparation for board exams. Clin Anat 2015; 28: 156-163

30 Hempel $D$, Stenger T, Campo Dell' Orto $M$ et al Analysis of trainees' memory after classroom presentations of didactical ultrasound courses. Crit Ultrasound J 2014; 6: 10

31 Teichgraber UK, Meyer JM, Poulsen Nautrup C et al. Ultrasound anatomy: a practical teaching system in human gross anatomy. Med Educ 1996; 30: 296-298

32 Wicke W, Brugger PC, Firbas W. Teaching ultrasound of the abdomen and the pelvic organs in the medicine curriculum in Vienna. Med Educ 2003; 37: 476

33 Brown B, Adhikari S, Marx J et al. Introduction of ultrasound into gross anatomy curriculum: perceptions of medical students. J Emerg Med 2012; 43: 1098-1102

34 Germany AoCpi. Vereinbarung von Qualitätssicherungsmaßnahmen nach $§ 135$ Abs. 2 SGB V zur Ultraschalldiagnostik. Dtsch Arztebl 2011; 108: A1450

35 Tolsgaard MG, Madsen ME, Ringsted C et al. The effect of dyad versus individual simulation-based ultrasound training on skills transfer. Med Educ 2015; 49: 286-295

36 Konge L, Albrecht-Beste E, Nielsen MB. Virtual-reality simulation-based training in ultrasound. Ultraschall Med 2014; 35: 95-97

37 Kromann CB, Jensen ML, Ringsted C. The effect of testing on skills learning. Med Educ 2009; 43: 21-27

38 Todsen T, Tolsgaard MG, Olsen BH et al. Reliable and valid assessment of point-of-care ultrasonography. Ann Surg 2015; 261: 309-315

39 Kratzer W, Pfeiffer M, Gebel $M$ et al. The research situation in abdominal sonography in the gastroenterology departments of university hospitals in the Federal Republic of Germany. Z Gastroenterol 2000 38: 833-834 836

40 Solomon SD, Saldana F. Point-of-care ultrasound in medical education-stop listening and look. N Engl J Med 2014; 370: 1083-1085

41 Dietrich CF. EFSUMB Course Book on Ultrasound (ECB). In: Dietrich CF ed. http://www.efsumb.org European Federation of Societies for Ultrasound in Medicine and Biology (EFSUMB) 2012;

42 Tuma JBR, Dietrich CF. EFSUMB Course Book on Ultrasound, Student edition (ECBSE). http://www.efsumb.org European Federation of Societies for Ultrasound in Medicine and Biology (EFSUMB) 2015

43 Dietrich CF. Examination techniques. www.efsumb.org European Federation of Societies of Ultrasound in Medicine and Biology (EFSUMB). 2015;

44 Dietrich $C F$, Rudd $L$. The EFSUMB website, a guide for better understanding. Med Ultrason 2013; 15: 215-223 